\title{
Antibiotic prescribing in primary care, adherence to guidelines and unnecessary prescribing - an Irish perspective
}

\author{
Marion Murphy ${ }^{1,2}$, Colin P Bradley and Stephen Byrne ${ }^{2^{*}}$
}

\begin{abstract}
Background: Information about antibiotic prescribing practice in primary care is not available for Ireland, unlike other European countries. The study aimed to ascertain the types of antibiotics and the corresponding conditions seen in primary care and whether general practitioners (GPs) felt that an antibiotic was necessary at the time of consultation. This information will be vital to inform future initiatives in prudent antibiotic prescribing in primary care.

Methods: Participating GPs gathered data on all antibiotics prescribed by them in 100 consecutive patients' consultations as well as data on the conditions being treated and whether they felt the antibiotic was necessary.

Results: 171 GPs collected data on 16,899 consultations. An antibiotic was prescribed at $20.16 \%$ of these consultations. The majority were prescribed for symptoms or diagnoses associated with the respiratory system; the highest rate of prescribing in these consultations were for patients aged 15-64 years (62.23\%). There is a high rate of $2^{\text {nd }}$ and $3^{\text {rd }}$ line agents being used for common ailments such as otitis media and tonsillitis. Amoxicillin, which is recommended as $1^{\text {st }}$ line in most common infections, was twice as likely to be prescribed if the prescription was for deferred used or deemed unnecessary by the GP.

Conclusion: The study demonstrates that potentially inappropriate prescribing is occurring in the adult population and the high rate of broad-spectrum antimicrobial agents is a major concern. This study also indicates that amoxicillin may be being used for its placebo effect rather than specifically for treatment of a definite bacterial infection.
\end{abstract}

\section{Background}

Antibiotic resistance is a major concern globally. Antibiotic consumption increases the likelihood for an individual to develop bacterial resistance [1]. The majority of antibiotic prescribing takes place in primary care and general practitioners (GPs) have been encouraged to prescribe antibiotics more rationally and to only give antibiotics when necessary [2].

Wide variation in antibiotic prescribing practices has been shown to exist in Europe demonstrating more than a threefold difference in antibiotic prescribing rates between countries, without any logical reasoning to explain the variation [3].

\footnotetext{
* Correspondence: stephen.byrne@ucc.ie

${ }^{2}$ Pharmaceutical Care Research Group, School of Pharmacy, University College Cork, Cork, Ireland

Full list of author information is available at the end of the article
}

In the Republic of Ireland (ROI), there has been increasing levels of resistance and antibiotic use [4]. Quinolone resistance rates in E.coli increased from 5\% in 2002 to $23 \%$ in 2008. Although ROI has seen small reductions in antibiotic use since 2009, high seasonal variation is still apparent which, in other countries, is also associated with high antibiotic consumption (France, Greece, Portugal and Italy) [3]. The reductions in antibiotic use seen in ROI have been associated with the stabilisation of rates of penicillin non-susceptible Streptococcus Pneumoniae (PNSP). The proportion of PNSP increased in ROI from $10.3 \%$ in 2004 to $23.1 \%$ in 2008 and decreased in 2010 to $18.2 \%$ [5]. The reductions in antibiotic use in ROI is low in comparison to that of Belgium and France where sustained campaigns have been associated with reductions of $36 \%$ and $26.5 \%$ respectively $[6,7]$. 
Non-clinical factors such as patient pressure have been shown to influence prescribing even in the absence of a clinical indication for an antibiotic [8,9]. The majority of ROI citizens must pay a fee to visit their GP and this has shown as a possible influence on the GP's decision to prescribe an antibiotic during the consultation [10].

The purpose of this study was to describe specific diagnoses for which systemic antibiotics are prescribed in primary care by GPs in the ROI, to assess adherence to recent national guidelines and gain more information on antibiotics that are prescribed unnecessarily.

\section{Methods}

\section{Study population}

The majority of GPs in ROI ( $>80 \%)$ are regular attendees of the small group continuing medical education (CME) network which is run by the Irish College of General Practitioners (ICGP). The CME network is provided in a format whereby GPs meet on a regular basis to learn in a mutually supportive group. The system is resourced by 37 CME tutors nationally with a target population of 1,934 GPs and an attendance of over $80 \%$ of all GPs in Ireland [11] Tutors run monthly meetings each year from September to May.

All CME tutors nationally and their CME groups were invited to participate in the study from October 2008 to April 2010. Each GP also completed an anonymous demographic questionnaire detailing their practice size, area, years in practice and post-graduate experience. All participating GPs were both state and privately funded. The state issues General Medical Service (GMS) cards to patients that are deemed unable to pay for medical care. Eligibility for GMS cards is dependent on a number of factors including income, marital status and age. In 2009, 33\% of the population in Ireland were GMS card holders [12]. All other patients (private patients) must pay for their medical care.

\section{Procedure}

Participating GPs gathered data on 100 consecutive consultations using a predefined piloted data collection proforma (Additional file 1). Out of hours consultations were not recorded. No data was collected during the summer months. Anonymised patient information was recorded including the age, gender and patient payment status. GPs recorded the reason for the consultation, or the diagnosis (if a diagnosis was reached). These were classified by the associated body system e.g. respiratory, skin, urinary tract disorders. All consultations associated with the respiratory system were further categorised into clinical entities and classified as symptoms (e.g. sore ear) or as diagnoses (e.g. otitis media). These categories are listed in Table 1. When an antibiotic was prescribed during the consultation, details of the prescription and
Table 1 Symptoms and diagnoses associated with the respiratory system

\begin{tabular}{|c|c|c|}
\hline Clinical Entity & Symptoms & Diagnosis \\
\hline Ear & Ear symptoms & $\begin{array}{l}\text { Otitis media } \\
\text { Otitis externa }\end{array}$ \\
\hline $\begin{array}{l}\text { Upper } \\
\text { Respiratory Tract }\end{array}$ & $\begin{array}{l}\text { Coryza/Rhinitis } \\
\text { Nasal congestion } \\
\text { Head cold } \\
\text { Post nasal drip } \\
\text { Sneezing }\end{array}$ & $\begin{array}{l}\text { Upper respiratory } \\
\text { tract infection }\end{array}$ \\
\hline
\end{tabular}

Throat

Sore throat Tonsillitis

Throat symptoms Pharyngitis

Trachetis

Peritonsula/Quinsy

Laryngitis

Croup

\begin{tabular}{lll}
$\begin{array}{l}\text { Sinus } \\
\text { Lower } \\
\text { Respiratory Tract }\end{array}$ & $\begin{array}{l}\text { Sinus pain/symptoms } \\
\text { Dyspnoea } \\
\text { Cough } \\
\text { Cough \& sputum/phlegm } \\
\text { Wheezing } \\
\text { Pleural effusion } \\
\text { Pleuritic Pain }\end{array}$ & $\begin{array}{l}\text { Sinusitis } \\
\text { Community acquired } \\
\text { pneumonia } \\
\text { Lower respiratory } \\
\text { tract infection } \\
\text { Bronchitis }\end{array}$ \\
Asthma/COPD & & $\begin{array}{l}\text { Asthma } \\
\text { COPD Exacerbation }\end{array}$ \\
Other & $\begin{array}{l}\text { Pyrexia/Fever/Temperature } \\
\text { Unspecified respiratory } \\
\text { tract infection }\end{array}$ & $\begin{array}{l}\text { Cystic Fibrosis } \\
\text { Bronchiolitis/RSV } \\
\text { Bronchiectasis }\end{array}$ \\
\hline
\end{tabular}

directions for use were recorded on the data collection proforma provided. GPs were also asked to record if they felt the antibiotic was necessary, not necessary or unsure. It was also recorded if the patient had received an antibiotic for the same condition in the previous two weeks. Each antibiotic prescribed and the reason for the consultation was compared to locally approved guidelines on community prescribing of antibiotics in Ireland [13]. These guidelines contain up-to-date evidence on the use of antibiotics for common conditions that present in primary care e.g. tonsillitis, otitis media. There were four types of deviations detected based on: (1) choice of antibiotic; (2) duration/frequency of antibiotic; (3) dosage of antibiotic; (4) diagnosis. Deviations due to diagnosis were recorded when antibiotics were prescribed for conditions not included in the guidelines, due to the lack of evidence to support their use (e.g. sore throat, cough). GPs were encouraged to provide additional information regarding the antibiotic prescription particularly if it was an influence on their decision (e.g. pregnancy, sensitivity analysis) and this was taken into account when deviations were assessed.

\section{National antibiotic consumption data}

Data regarding antibiotic consumption in ROI during the time of the study (October 2008-April 2010) was provided by the Health Protection Surveillance Centre (HPSC). This data is from IMS Health, a pharmaceutical 
market research company and contains monthly wholesaler to retail pharmacy sales data from over $95 \%$ of the wholesalers and manufacturers in Ireland. Antibiotic consumption was measured in Defined Daily Dose (DDD) which is the assumed average maintenance dose per day for a drug used for its main indication in adults.

\section{Analysis}

Data was analysed using Microsoft Office Excel ${ }^{\circledR}$ (2007) and Predictive Analytics SoftWare (PASW ${ }^{\circledR}$, Chicago, Illinois, USA) version 17.0. A sample (10\%) was doublechecked for coding entry errors. Data collected was tested for normality and parametric/non-parametric tests were used as appropriate. The Pearson's chi-squared tests were performed to compare categorical variables. Odds ratios (ORs) with corresponding 95\% confidence intervals (CIs) were calculated using logistic regression.

HPSC data was used to compare the pattern of antibiotic usage between the national picture and the study GP population.

\section{Ethical approval and Informed Consent}

The study was approved by the Clinical Research Ethics Committee of the Cork Teaching Hospitals. Informed consent was obtained from all GPs by participation in the study.

\section{Results}

Data were collected from 171 GPs nationally who recorded information on 16,899 consultations. The mean $( \pm$ SD) number of consultations recorded per GP was $98.82 \pm 5.37$. The majority of GPs who participated completed a demographics questionnaire $(84.80 \%, 145)$. All GPs were from combined GMS and private practices and situated in various settings: urban $(37.24 \%, 54)$, rural $(24.83 \%, 36)$ and mixed (37.93\%, 55)

The majority of attendees were females $(58.80 \%, 9,936)$ and held a GMS card (53.83\%, 9,096).

An antibiotic was prescribed in one-fifth of consultations recorded $(20.16 \%, 3,407)$. A quarter of these $(25.74 \%$, 877 ) were prescribed to a child between the ages of 1 and 14 years. A small proportion had received an antibiotic for the same presenting complaint in the previous two weeks prior to the consultation $(8.22 \%, 280)$.

\section{Choice of antibiotic}

Co-amoxiclav, amoxicillin and clarithromycin were the most commonly prescribed antibiotics and this was also reflected in the national data (Table 2). With the exception of doxycycline and lymecycline, the pattern of antibiotic usage in terms of ranking was very similar.

\section{Reasons for an antibiotic prescription}

Symptoms/diagnoses associated with the respiratory system accounted for the majority of antibiotic prescriptions $(64.72 \%, 2,205)$, followed by skin $(10.21 \%, 348)$ and urinary tract disorders $(8.63 \%, 294)$. Overall, $22.63 \%$ of consultations $(3,824)$ recorded either a diagnosis or symptoms of the respiratory system. The majority of these consultations received an antibiotic prescription (57.66\%, 2,205). Children aged 4-14 years had the highest consultation rate where a respiratory symptom/diagnosis was recorded $(33.94 \%, 1,298)$. Patients under the age of 65 were twice as likely to consult with respiratory symptoms/diagnoses than younger patients (OR 2.08, 95\% CI 1.87-2.23).

Children aged from $0-14$ years had the lowest percentage rate of antibiotic prescribing when presenting with respiratory symptoms $(52.25 \%, 767)$. The highest percentage was seen for patients aged 15-64 (62.23\%, 1,104) (Figure 1). In consultations with a respiratory diagnosis, $66.08 \%(1,420)$ resulted in an antibiotic prescription, in comparison with $48.22 \%$ (787) of those with respiratory symptoms. High prescribing rates $(>85 \%)$ were seen in patients with throat, ear and sinus infections recorded. There was also considerable antibiotic prescribing for conditions not included in the guidelines such as upper respiratory tract infection (URTI) $(33.10 \%, 187)$, cough $(35.82 \%, 173)$ and sore throat $(53.11 \%$, 128) (Figure 2).

\section{Adherence to guidelines}

The majority of antibiotic prescriptions were not strictly in accordance to guidelines $(78.05 \%, 2,659)$. Nearly half of the deviations were related to the diagnosis/reason given for the consultation $(46.71 \%, 1,242)$. This correlated with the high use of antibiotics for respiratory symptoms which are not included in the guidelines. The choice of the antibiotic was also a recurrent deviation $(30.27 \%, 805)$. These included deviations such as the use of $2^{\text {nd }}$ and $3^{\text {rd }}$ line agents for infections as opposed to the $1^{\text {st }}$ line choice. Antibiotic prescriptions for common respiratory infections seen in the community corresponded with the recommended first-line choice in less than $50 \%$ of all prescriptions (Table 3). Co-amoxiclav accounted for almost a quarter of the prescriptions in tonsillitis $(25.09 \%, 74)$, otitis media $(25.46 \%, 84)$, bronchitis $(27.75 \%, 187)$, sinusitis $(23.71 \%, 46)$ and urinary tract infections $(21.82 \%, 48)$.

The majority of antibiotic prescriptions were for immediate use $(84.00 \%, 2,862)$; co-amoxiclav (23.72\%, $679)$, amoxicillin $(18.20 \%, 521)$ and clarithromycin $(9.54 \%, 273)$ were the most common antibiotics prescribed. There were $470(13.80 \%)$ antibiotic prescriptions for deferred use (2.05\% (70) were not recorded). The majority of these prescriptions were amoxicillin $(39.57 \%, 186)$, followed by co-amoxiclav $(19.57 \%, 92)$ 
Table 2 Comparison of the most common antibiotics consumed nationally in primary care and the most common antibiotics prescribed by General Practitioners in the study. (DDD: defined daily dose; HPSC: Health Protection Surveillance Centre)

\begin{tabular}{|c|c|c|c|c|c|c|}
\hline \multirow[t]{2}{*}{ Antibiotic } & \multicolumn{3}{|c|}{ National consumption data (HPSC) } & \multicolumn{3}{|c|}{ GP Study } \\
\hline & Rank & DDD & $\%$ & Rank & Reported prescriptions & $\%$ \\
\hline Co-amoxiclav & 1 & 765,235 & 27.01 & 1 & 792 & 23.66 \\
\hline Amoxicillin & 2 & 448,362 & 15.83 & 2 & 719 & 21.48 \\
\hline Clarithromycin & 3 & 386,060 & 13.63 & 3 & 308 & 9.20 \\
\hline Doxycycline & 4 & 176,445 & 6.23 & 9 & 81 & 2.42 \\
\hline Flucloxacillin & 5 & 128,998 & 4.55 & 5 & 231 & 6.90 \\
\hline Phenoxymethylpenicillin & 6 & 113,971 & 4.02 & 4 & 233 & 6.96 \\
\hline Cefaclor & 7 & 108,434 & 3.83 & 6 & 173 & 5.17 \\
\hline Trimethoprim & 8 & 107,384 & 3.79 & 7 & 131 & 3.91 \\
\hline Lymecycline & 9 & 97,918 & 3.46 & 19 & 20 & 0.60 \\
\hline Erythromycin & 10 & 89,771 & 3.17 & 8 & 82 & 2.45 \\
\hline Ciprofloxacin & 12 & 84,981 & 3.00 & 10 & 78 & 2.33 \\
\hline Other antibacterials & & 325,666 & 11.49 & & 500 & 14.93 \\
\hline
\end{tabular}

and phenoxymethylpenicillin $(9.15 \%, 43)$. When a deferred prescription was issued, it was twice as likely to be for amoxicillin as any other antibiotic (OR 2.18, 95\% CI 1.78-2.66).

\section{Necessary antibiotics}

Most of the antibiotics that were prescribed were deemed to be necessary for the condition they were being prescribed for $(71.76 \%, 2,445)$ and almost a quarter of these prescriptions were for co-amoxiclav (24.09\%, 589). There were 315 (9.25\%) prescriptions that were thought not to be necessary and prescribers were unsure of 602 (17.67\%) prescriptions; amoxicillin was the most common antibiotic choice in these instances $(36.19 \%, 114$ and $29.73 \%, 179$ respectively) (Figure 3). Amoxicillin was twice as likely to be prescribed when the antibiotic was thought

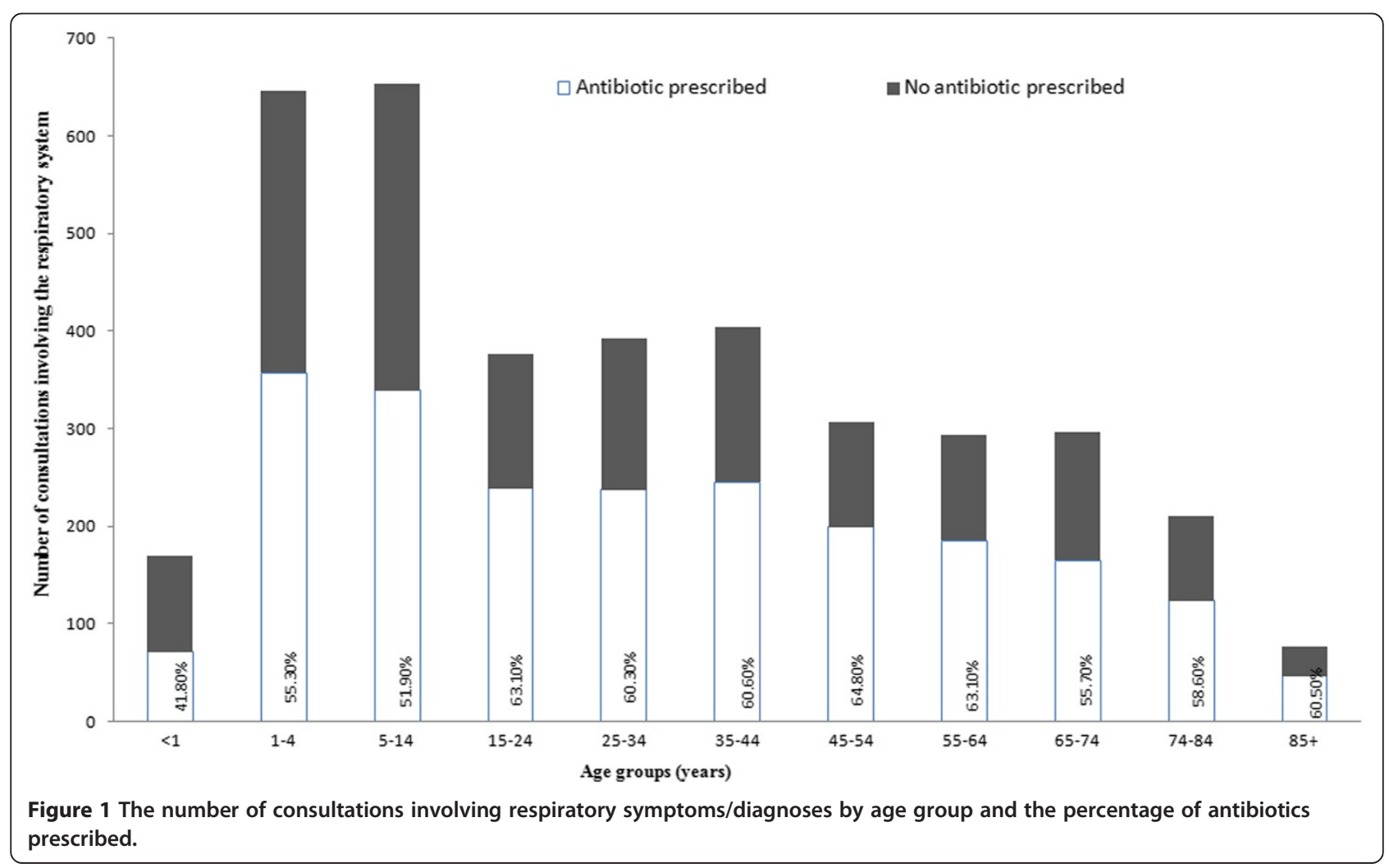




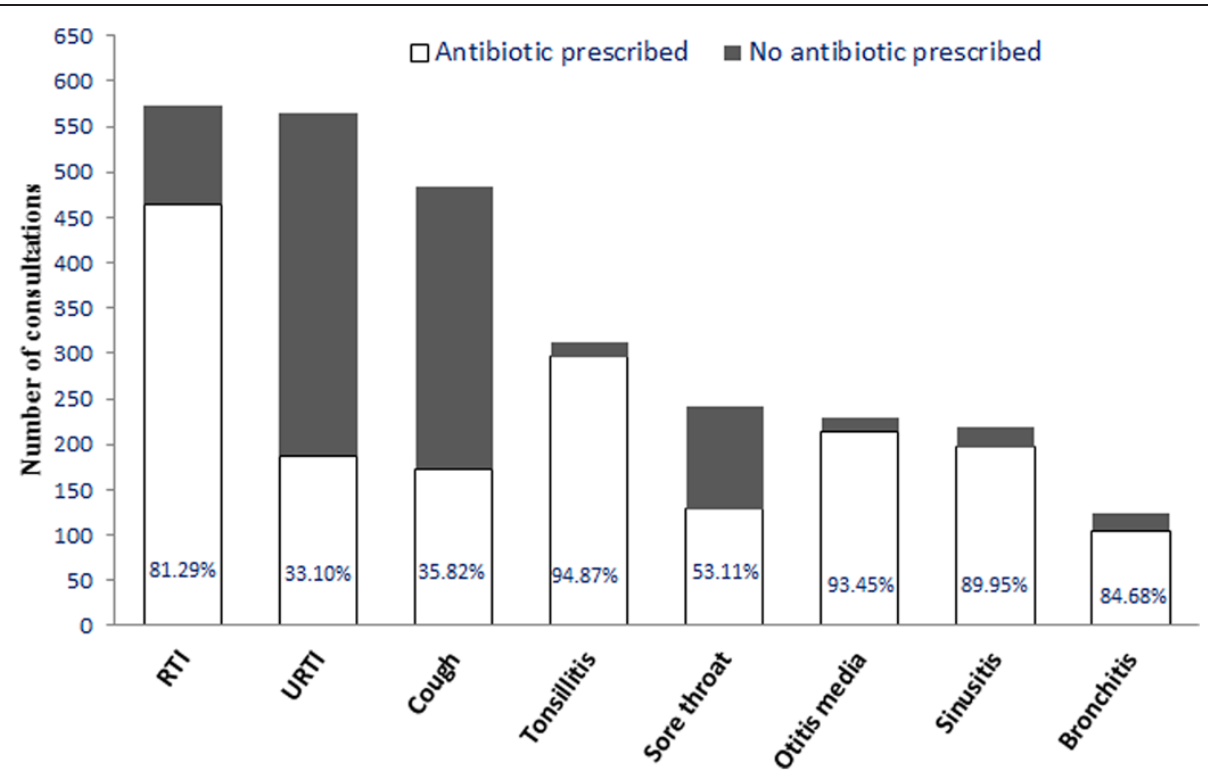

Figure 2 Common respiratory conditions and the percentage of antibiotic prescribing for each condition.

to be unnecessary (OR 2.86, 95\% CI 2.22-3.69). URTI was the most common reason for an unnecessary prescription $(17.46 \%, 55)$ followed by cough $(12.06 \%, 38)$ and flu-like symptoms $(9.52 \%, 30)$.

\section{Discussion}

Overall, this study has identified the huge burden of respiratory symptoms/conditions in general practice in
Ireland. Nearly a quarter of all the consultations recorded were due to respiratory illnesses $(22.63 \%)$. This is higher than the UK where only approximately $15 \%$ of GP consultations are due to these ailments [14]. As with other countries, the most common cause for an antibiotic prescription is due to symptoms or conditions relating to the respiratory system. Overall, children (1-14 years) received the highest proportion of the antibiotic prescriptions and this is

Table 3 Percentages of first-line, second-line and remaining antibiotics according to Irish national guidelines

\begin{tabular}{|c|c|c|}
\hline Guidelines & First line (\%) & Second line/remaining (\%) \\
\hline Tonsillitis $(n=295)$ & Phenoxypenicillin (42.71) & $\begin{array}{l}\text { Clarithromycin* (5.76) } \\
\text { Amoxicillin (19.66) } \\
\text { Co-amoxiclav (25.09) } \\
\text { Other (6.78) }\end{array}$ \\
\hline Otitis media $(n=330)$ & Amoxicillin (42.12) & $\begin{array}{l}\text { Clarithromycin* (19.70) } \\
\text { Co-amoxiclav (25.46) } \\
\text { Cephalosporins (6.97) } \\
\text { Other (5.46) }\end{array}$ \\
\hline Sinusitis $(n=194)$ & $\begin{array}{l}\text { Amoxicillin (15.46) } \\
\text { Doxycycline (24.23) }\end{array}$ & $\begin{array}{l}\text { Clarithromycin* (18.56) } \\
\text { Co-amoxiclav (23.71) } \\
\text { Cephalosporins (13.40) } \\
\text { Other (4.64) }\end{array}$ \\
\hline Bronchitis/Cough $(n=674)$ & $\begin{array}{l}\text { Amoxicillin (36.50) } \\
\text { Doxycycline }(0.00)\end{array}$ & $\begin{array}{l}\text { Clarithromycin* (21.22) } \\
\text { Co-amoxiclav (27.75) } \\
\text { Cephalosporins (10.68) } \\
\text { Other (3.86) }\end{array}$ \\
\hline Community acquired pneumonia $(n=25)$ & $\begin{array}{l}\text { Amoxicillin }(0.00) \\
\text { Clarithromycin }(44.00) \\
\text { Doxycycline }(0.00)\end{array}$ & $\begin{array}{l}\text { Co-amoxiclav (44.00) } \\
\text { Cephalosporins }(4.00) \\
\text { Other (8.00) }\end{array}$ \\
\hline Urinary Tract infection(uncomplicated female) $(n=220)$ & $\begin{array}{l}\text { Trimethoprim (32.73) } \\
\text { Nitrofurantoin (7.73) }\end{array}$ & $\begin{array}{l}\text { Cephalosporins (20.00) } \\
\text { Co-amoxiclav (21.82) } \\
\text { Quinolones (10.91) } \\
\text { Other (6.82) }\end{array}$ \\
\hline
\end{tabular}




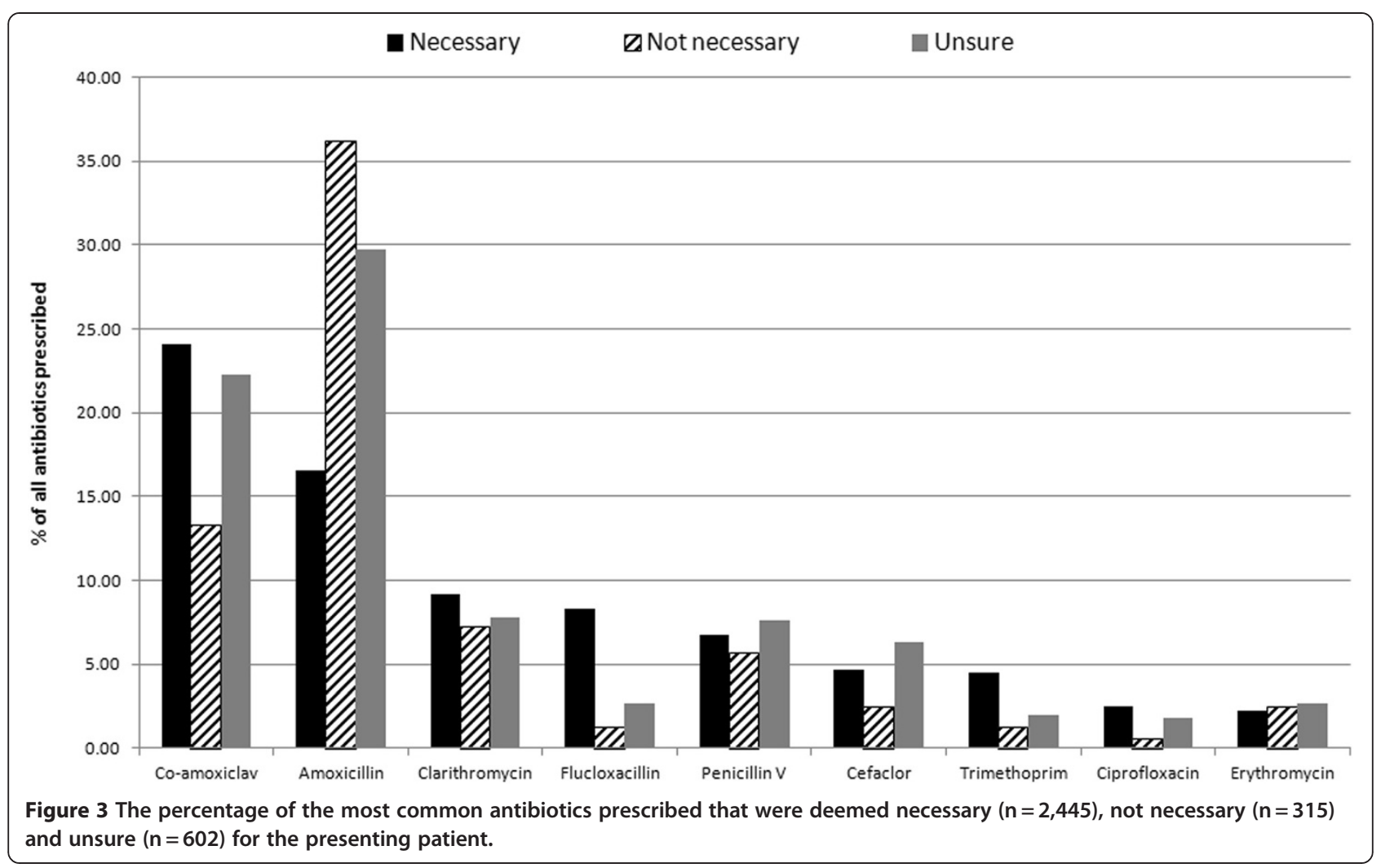

probably due to the high number of consultations involving the respiratory system in this age group. Surprisingly, patients (15-64 years) presenting to the GP have the highest rate of antibiotic use per respiratory consultation, with over $60 \%$ of these consultations receiving an antibiotic prescription. Other studies have also shown that children visit their GP more often with respiratory conditions but in proportion do not receive more antibiotics than adults $[14,15]$. Research has also shown that antibiotics are not justified to reduce the risk of serious complications of these conditions but may be warranted for those over the age of 65 where the number needed to treat to prevent pneumonia post chest infection is much lower than younger age groups (39 vs 119) [16]. Therefore it would be expected to see higher rates of antibiotic use in the elderly cohort. Possible explanations for the higher rates of antibiotic use seen in younger patients (15-64 years) may be due to structure of the health care system in ROI. The elderly, the very young ( $<5$ years) and the most socio-economically disadvantaged are more likely to be GMS card holders due the eligibility criteria. The average cost for a GP consultation for a private patient in ROI is $€ 51$ [17]. GPs have been shown to overestimate the patient's expectation for a prescription and this influences the decision to prescribe [18]. This may be more evident in ROI as GPs may be more sensitive to patients' expectations if the patient is paying for the consultation
[10]. It may be particularly difficult for the GP not to give a prescription under these circumstances; they may provide a prescription to reduce the need for reconsultation if required. Diagnostic uncertainty and fear of negligence have also been quoted as drivers of antibiotic overprescribing [19].

There is considerable variation in antibiotic prescribing between the respiratory clinical entities with a substantial proportion of prescribing occurring for respiratory symptoms. GPs may have had an inclination to label symptoms as a diagnosis to gain endorsement of their prescribing; diagnostic labelling has been shown to be associated with high levels of antibiotic prescribing [20].

Antibiotics are not recommended for symptoms such as cough, sore throat but a high level of prescribing was recorded in these conditions. This is the reason why the majority of deviations from guidelines in this study were due to the diagnosis/reason for consultation. A study in Canada showed that $5 \%$ of URTI consultations received an antibiotic; this is in contrast to $33.10 \%$ in this study [21]. The majority of consultations that diagnosed an ear infection received an antibiotic (89.49\%); USA and the UK have similar rates while the Netherlands has much lower rates of $56 \%$ [22,23]. In a recent study in the USA, 30\% of children diagnosed with a viral respiratory infection were prescribed an antibiotic [24]. 
In comparison to other countries, the level of agreement to guidelines is low. However, these guidelines have been recently developed and should be disseminated widely to have any impact. In the Netherlands, about three-quarters of antibiotics prescribed are first-line choice [25]. A third of patients who had been prescribed an antibiotic in the previous two weeks (i.e. for the same illness) had been prescribed co-amoxiclav which is recommended as second-line (broad-spectrum antibiotic); this could suggest that these cases were not treatment failures but rather viral illnesses.

The majority of tonsillitis presentations are not being treated with narrow-spectrum antibiotics as considered appropriate. This has a major impact on increasing resistance. The usage of amoxicillin for otitis media (first line) is lower than expected at $42.42 \%$, other countries in Europe have rates of $82 \%$ with co-amoxiclav only used in $7 \%$ of cases [23]. Studies have described how a reduction in antibiotic usage carries a parallel decrease in resistance $[26,27]$. The high incidence of co-amoxiclav has been shown in other studies in ROI, with the consumption increasing by $80 \%$ from $2000-2005$ while the use of amoxicillin decreased by $9 \%$ in the same time period $[28,29]$. In the absence of guidance from public health bodies, it could be argued that third-party representatives from the pharmaceutical industry may have contributed to the high usage of second line and third line agents [30].

In contrast to the high rates of co-amoxiclav, amoxicillin was more likely to be prescribed than other antibiotics when the prescription was for deferred/delayed use and also when the GP did not think that the antibiotic was necessary for the condition being treated. It could be argued that this study provides possible evidence that GPs prescribe antibiotics such as amoxicillin as 'impure placebos' or 'pseudoplacebos', these agents consist of biologically active agents that have specific efficacy for some conditions but used as a placebo for another condition i.e. antibiotics for probable viral infections such as URTI and cough. A survey in Denmark found that 70\% of GPs had prescribed antibiotics as a placebo intervention in the previous year [31]. The most common reason quoted for this was to 'follow the wish of the patient and avoid conflict' [31]. Prescribers also report generally positive attitudes about the use of medication to promote the placebo effect [32].

This study clearly indicates that guidelines need to be disseminated at a local level with a focus to reduce antibiotic prescribing for minor respiratory conditions and reduce broad-spectrum antibiotic prescribing whenever necessary. Prescribing a course of antibiotics increases the patient's risk of developing bacterial resistance for up to a year [1]; GPs should be mindful of this issue when prescribing antibiotics that are not necessary. It is particularly important to increase public awareness regarding appropriate antibiotic use to ease patient pressure on GPs to prescribe.

\section{Strengths and weaknesses}

The data from this study is valuable as it is the first time diagnoses are linked to antibiotic consumption in ROI and also details prescribing behaviour for both private and GMS card holders. In ROI, private patients are not required to register with their GP and are therefore free to visit any GP they wish; patients do not have a unique identifier. Therefore, it is currently not possible for routine data collection to take place from electronic sources in ROI.

The reason for the consultation was recorded in free text words to include all types of reasons provided for an antibiotic prescription. Other studies have quoted that a large proportion of primary care visits are difficult to label with a precise code and also require GPs to participate in training in coding [14]. Therefore in this study, we were unable to differentiate between multiple consultations pertaining to the same episode. However, the number of previous antibiotics for the same episode was low.

The population of GPs in this study may be skewed towards those with an interest in the area of antibiotic prescribing as their participation was not mandatory as part of their CME group. However, the national data from the time of study reflects similar usage patterns of antibiotics. A possible explanation for the notable higher usage of doxycycline and lymecycline in the national dataset could be explained by dermatologists prescribing these agents in the outpatient setting.

\section{Conclusion}

This study provides evidence that antibiotics are probably not being used as prudently in the community in ROI as they may be other countries. Children present to their GP with respiratory symptoms more often than adults, but higher rates of antibiotic prescribing occur in adults with similar symptoms. This study also shows that amoxicillin may be being used for its placebo effect rather than as specific treatment for bacterial infection.

\section{Additional file}

Additional file 1: Data Collection form.pdf. Description of data: This is a copy of the data collection form which participating GPs completed for the purposes of this study.

\section{Competing interests}

The authors declare that they have no conflict of interest.

\section{Acknowledgements}

The authors would like to thank the GPs and the CME groups who participated in the study. Thanks to Dr. Rob Cunney and Ajay Oza (HPSC) for providing national consumption data. The study was supported by the Health Service Executive, Ireland.

\section{Author details}

${ }^{1}$ Department of General Practice, School of Medicine, University College Cork, Cork, Ireland. ${ }^{2}$ Pharmaceutical Care Research Group, School of Pharmacy, University College Cork, Cork, Ireland. 


\section{Authors' contributions}

MM distributed the data collection booklets, analysed the data and drafted the original manuscript. All authors critically reviewed the manuscript and approved publication submission.

Received: 27 November 2011 Accepted: 28 May 2012 Published: 28 May 2012

\section{References}

1. Costelloe C, Metcalfe C, Lovering A, Mant D, Hay AD: Effect of antibiotic prescribing in primary care on antimicrobial resistance in individual patients: systematic review and meta-analysis. BMJ 2010, 340:c2096.

2. National Disease Surveillance Centre: S.A.R.I., Strategy for the Control of Antimicrobial Resistance in Ireland. 2001.[ http://www.hpsc.ie/hpsc/A-Z/ MicrobiologyAntimicrobialResistance/

StrategyforthecontrolofAntimicrobialResistanceinlrelandSARI/KeyDocuments/ File,1070,en.pdf/]

3. Goossens H, Ferech M, vander Stichele R, Elseviers M: Outpatient antibiotic use in Europe and association with resistance: a cross-national database study. Lancet 2005, 365:579-587.

4. Van de Sande-Bruinsma N, Grundmann H, Verloo D, Tiemersma E, Monen J, Goossens H, Ferech M: Antimicrobial drug use and resistance in Europe. Emerg Infect Dis 2008, 14:1722--1730.

5. Irish European Antimicrobial Resistance Surveillance Network Steering Group: EARS-Net Report Report for Quarter 4 2010. 2011. [ http://www. hpsc.ie/hpsc/A-Z/MicrobiologyAntimicrobialResistance/ EuropeanAntimicrobialResistanceSurveillanceSystemEARSS/ EARSSSurveillanceReports/2010Reports/File,12542,en.pdf]

6. Goossens H, Guillemot D, Ferech M, Schlemmer B, Costers M, van Breda M, Baker LJ, Cars O, Davey PG: National campaigns to improve antibiotic use. Eur J Clin Pharmacol 2006, 62:373-379.

7. Sabuncu E, David J, Bernède-Bauduin C, Pépin S, Leroy M, Boëlle P-Y, Watier L, Guillemot D: Significant Reduction of Antibiotic Use in the Community after a Nationwide Campaign in France, 2002-2007. PLoS Med 2009, 6:e1000084

8. Macfarlane J, Holmes W, Macfarlane R, Britten N: Influence of patients' expectations on antibiotic management of acute lower respiratory tract illness in general practice: questionnaire study. BMJ 1997, 315:1211-1214.

9. Cotter M, Daly L: Antibiotic Prescription Practices of General Practitioners Ir Med J 2007, 100:598-601.

10. Murphy M, Byrne S, Bradley CP: Influence of patient payment on antibiotic prescribing in Irish general practice: a cohort study. Br J Gen Pract 2011, 61:e549-e555.

11. O'Dowd T, O'Kelly F, O'Kelly M: Structure of General Practice in Ireland 19822005. Dublin:Irish College of General Practitioners; 2006.

12. Health Service Executive: Annual Report and Financial Statements. Dublin: 2009

13. Community Antibiotic Stewardship Group: Management of Infection Guidance for Primary Care in Ireland. Dublin:Health Protection Surveillance Centre; 2011.

14. Hak E, Rovers M, Kuyvenhoven M, Schellevis F, Verheij T: Incidence of GP- diagnosed respiratory tract infections according to age, gender and high-risk co-morbidity: the Second Dutch National Survey of General Practice. Fam Pract 2006, 23:291-294.

15. Akkerman AE, van der Wouden JC, Kuyvenhoven MM, Dieleman JP, Verheij TJM: Antibiotic prescribing for respiratory tract infections in Dutch primary care in relation to patient age and clinical entities. J Antimicrob Chemother 2004, 54:1116-1121.

16. Petersen I, Johnson AM, Islam A, Duckworth G, Livermore DM, Hayward AC: Protective effect of antibiotics against serious complications of common respiratory tract infections: retrospective cohort study with the UK General Practice Research Database. BMJ 2007, 335:982

17. National Consumer Agency: Doctors and dentists survey. 2010 [ http://corporate.nca.ie/eng/Research_Zone/price-surveys/ March 2010 doctors and dentists prices survey html]

18. Welschen I, Kuyvenhoven M, Hoes A, Verheij T: Antibiotics for acute respiratory tract symptoms: patients' expectations, GPs' management and patient satisfaction. Fam Pract 2004, 21:234-237.

19. McDonell Norms Group: Antibiotic overuse: the influence of social norms. J Am Coll Surg 2008, 207:265-275.
20. Van Duijn H, Kuyvenhoven M, Tiebosch H, Schellevis F, Verheij T: Diagnostic labelling as determinant of antibiotic prescribing for acute respiratory tract episodes in general practice. BMC Fam Pract 2007, 8:55

21. Jelinski S, Parfrey P, Hutchinson J: Antibiotic utilisation in community practices: guideline concurrence and prescription necessity. Pharmacoepidemiol Drug Saf 2005, 14:319-326.

22. Froom J, Culpepper L, Green LA, de Melker RA, Grob P, Heeren T, van Balen F: A cross-national study of acute otitis media: risk factors, severity, and treatment at initial visit. Report from the International Primary Care Network (IPCN) and the Ambulatory Sentinel Practice Network (ASPN). J Am Board Fam Pract 2001, 14:406-417.

23. Akkerman AE, Kuyvenhoven MM, van der Wouden JC, Verheij TJM: Analysis of under- and overprescribing of antibiotics in acute otitis media in general practice. J Antimicrob Chemother 2005, 56:569-574

24. Nadeem Ahmed M, Muyot MM, Begum S, Smith P, Little C, Windemuller FJ: tibiotic Prescription Pattern for Viral Respiratory IIIness in Emergency Room and Ambulatory Care Settings. Clin Pediatr 2010, 49:542-547.

25. Ong DSY, Kuyvenhoven MM, van Dijk L, Verheij TJM: Antibiotics for respiratory, ear and urinary tract disorders and consistency among GPs. J Antimicrob Chemother 2008, 62:587-592.

26. Seppala H, Klaukka T, Vuopio-Varkila J, Muotiala A, Helenius H, Lager K, Huovinen P: The effect of changes in the consumption of macrolide antibiotics on erythromycin resistance in group $A$ streptococci in Finland. Finnish Study Group for Antimicrobial Resistance. N Engl J Med 1997, 337:441-446.

27. Butler CC, Dunstan F, Heginbothom M, Mason B, Roberts Z, Hillier S, Howe R, Palmer S, Howard A: Containing antibiotic resistance: decreased antibiotic-resistant coliform urinary tract infections with reduction in antibiotic prescribing by general practices. Br J Gen Pract 2007, 57:785-792

28. Barry M: Economies in Drug Usage in the Irish Healthcare Setting. Dublin 2009.

29. McGowan B, Bergin C, Bennett K, Barry M: Utilisation of antibiotic therapy in community practice. Ir Med J 2008, 101:273-276.

30. Søndergaard J, Vach K, Kragstrup J, Andersen M: Impact of pharmaceutical representative visits on GPs' drug preferences. Fam Pract 2009, 26:204-209.

31. Hróbjartsson A, Norup M: The Use of Placebo Interventions in Medical Practice-A National Questionnaire Survey of Danish Clinicians. Eval Health Prof 2003, 26:153-165.

32. Tilburt JC, Emanuel EJ, Kaptchuk TJ, Curlin FA, Miller FG: Prescribing "placebo treatments": results of national survey of US internists and rheumatologists. BMJ 2008, 337:a1938.

doi:10.1186/1471-2296-13-43

Cite this article as: Murphy et al:: Antibiotic prescribing in primary care, adherence to guidelines and unnecessary prescribing - an Irish perspective. BMC Family Practice 2012 13:43.

\section{Submit your next manuscript to BioMed Central and take full advantage of:}

- Convenient online submission

- Thorough peer review

- No space constraints or color figure charges

- Immediate publication on acceptance

- Inclusion in PubMed, CAS, Scopus and Google Scholar

- Research which is freely available for redistribution 